\title{
Operational Mechanism of CDIO Innovation and Practice Center and the Design of Experiment in Courses "Process of Industry Production"
}

\author{
Chen Zhanlin ${ }^{1, a}$, Zeng Lingsheng ${ }^{1}$, Zhang Ziqiang ${ }^{1}$, Bao Nengsheng ${ }^{1}$, Xie \\ Xuheng $^{1}$, Chen Xuetao ${ }^{1}$, Wu Baozhao ${ }^{1}$ \\ ${ }^{1}$ Department of Mechatronics Engineering, College of Engineering, Shantou University Shantou, \\ China \\ azlchen@stu.edu.cn
}

\begin{abstract}
Keywords: EIP-CDIO, CDIO project, open management, experiment parameter.
\end{abstract}
\begin{abstract}
In recent years, with the introduction of CDIO engineering education reform idea and the implementation of "Excellent Engineer Education and Training Plan", the higher requirements are put forward for the construction and operational mechanism of collegiate laboratory and experiment teaching. In this paper, combining with the several years' experience in construction of CDIO innovation and practice center in the department of mechatronics engineering, college of engineering, Shantou University, focuses on the introduction of its operational mechanism, then illustrates how to design the experiments under the current mechanism by the case of the experiment in course "process of industry production". The case shows that the students' comprehensive qualities have been enhanced, for example: students have wonderfully completed given teaching projects and won a number of honors in technological competitions at home and abroad.
\end{abstract}

\section{Introduction}

CDIO engineering education mode is the latest results of the international engineering education reform in recent years. CDIO stands for Conceive, Design, Implement, and Operate, which is based on the product lifecycle from research and development to operation, let students study engineering by active learning and practice, and there is organic connection between courses. Since 2005, college of engineering in Shantou University put forward design-oriented EIP-CDIO engineering education mode by application CDIO concept [1]. Shantou University has become to implement design-oriented EIP-CDIO engineering education mode since 2006, and the department of mechatronics engineering, college of engineering, Shantou University, has firstly joined in the "Excellent Engineer Education and Training Plan" construction which launched by Ministry of Education of P.R. China and the Chinese Academy of Engineering in june,2010. CDIO engineering education mode is similar with "Excellent Engineer Education and Training Plan" in cultivating concepts and cultivating targets, and the former can be referred to by the latter [2].

In profession cultivating of the EIP-CDIO engineering education mode, by integrating teaching factors and taking system concept as a guide, the students' personal skill, team skill and system regulating and controlling skill are trained based on experimental and exploratory project design [1]. Therefore, it is necessary to set up a platform adapting to EIP-CDIO engineering education mode, which services for students' project implementation and experiment teaching. In this context, the CDIO Innovation and Practice Center was established in the department of mechatronics engineering, college of engineering, Shantou University in 2011. Its aim is to provide a superior public service platform for technological innovation and practical activities of students. It is $1500 \mathrm{~m}^{2}$, and there are five machining centers, four CNC lathes, five milling machines, five engine lathes and two 3D Printers in it, which offers superior environment for EIP-CDIO engineering education reform.

\section{Operational Mechanism of CDIO Innovation and Practice Center}

Students in the department of mechatronics engineering, college of engineering, Shantou University, can take part in the competitive projects at home and abroad, and the specified teaching projects: first, 
secondary and third level projects. The specified teaching projects must be finished. The first level projects are the projects which contain the professional main core courses and the skill demands; Secondary level projects are the projects which contain related core courses and the skill demands; Third level projects are the projects for single course, which aims to enhance understanding and cultivate related skills, third level projects is set up or not, and its form adopted are decided by each course according to need. Fig. 1 shows the first level projects are the artery, the secondary level projects are the branches and the third level projects and core courses are the foundation [2].

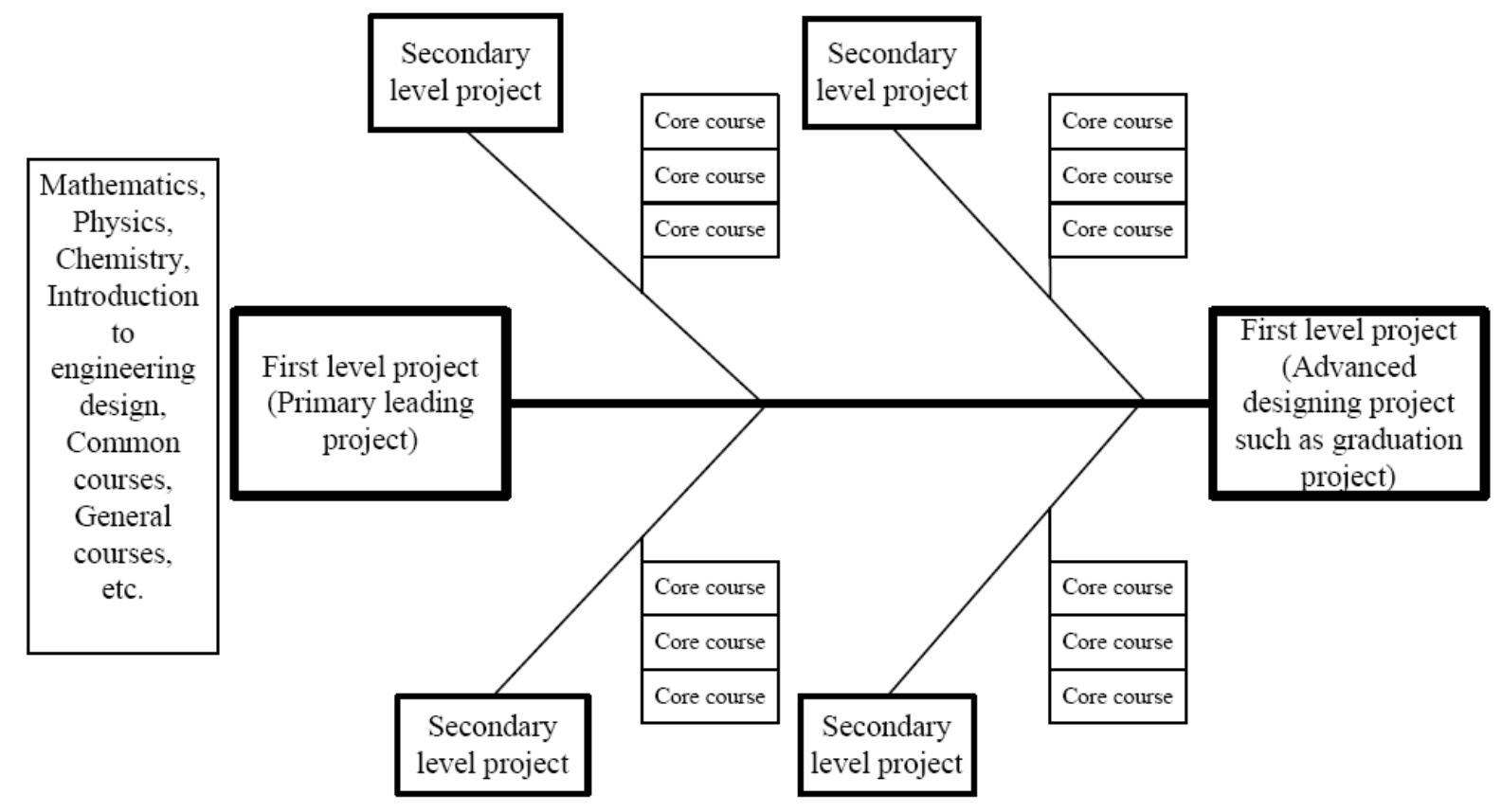

Fig. 1.Professional CDIO cultivating skeleton diagram

Students, who have adequate energy, can take part in the competition projects at home and aboard voluntarily such as: "National Match of Student Mechanical Creative Design", "CDIO Academy Students Project Competition in 2013". These competition projects can provide more practice opportunities for students, open their view, improve their confidence, and test their skills.

In order to make above projects to implement smoothly, the center's operational mechanism is as follows:

Regulation of site opening for students all day. The center is divided into three functional areas: discussion, manufacture, assembling. During the whole process of project implementation students will meet lots of problems in project design, part processing plans, machine installation and adjustment. The project team can discuss how to solve them in the discussion area. In the middle of the project, they have to manufacture their designed parts in the manufacture area. And at last, they assemble all of parts into a machine and check if it is qualified or not in the assembling area.

The center not only satisfies students' requirements of projects implementation, but also serves for experiment teaching and professional skill training of students. Since the opening hours of center cannot always meet students' demands. What is more, different grades and teams have diverse projects.

In a word, the center should meet students' project demands anytime under the condition without affecting experiment teaching. Consequently, it is necessary for the center to open for students all day. The CDIO Innovation and Practice Center implements the management of project team responsibility system which is together managed by teachers and students. In order to prevent unrelated persons going into the center, it carries out the management of door control. People served by the center can enter it by the Shantou University campus card.

Security management regulation of equipment operation. Students, who have systematically accepted training of professional technical ability of engineering, can take part in the examination of professional technical ability hosted by High-level Technical School of East Guangdong. They can 
attain a certificate of professional technical ability awarded by Department of Human Resource and Social Security of Guangdong Province after passing the examination. These students can operate machines alone when instructors are absence, and have a certain priority in competition projects and the right to use of machines. It is not only easy to manage for the center, but also can guarantee students' security and encourage their enthusiasm.

However, students not trained by the professional technical ability also can operate some machines in the center when instructors are absent now. In order to limit students' right of using machines and guarantee their security, the center is going to purchase a management system of experiment device which can control all of machines in the center. Persons only authorized by the center can operate the machines.

\section{The Function of Experiment Teaching to CDIO Related Skills Cultivating of Students}

Experiment teaching is one of the teaching methods, which is conducive to help students to understand, master and apply theoretical knowledge; cultivate students the style integrating theory with practice, rigorous and pragmatic science attitude and independently operative skill; cultivate their innovation skill and consciousness; cultivate their thought character and habit to engage in science research in the future; improve their comprehensive science quality [3].

The CDIO Innovation and Practice Center not only undertakes the "metalworking practice" teaching task, but also bears the experiment teaching of the courses such as: "CNC lathe", "process of industry production", "non-traditional machining", and "interchangeability and measuring technology foundation". To illustrate experiment teaching how to cultivate CDIO related skills of students, the experiment teaching in course "process of industry production" is taken as an example as follows:

The course "process of industry production" is an important professional course in department of mechatronics engineering, college of engineering, Shantou University. It is a new professional course on the basis of original "manufacturing technology foundation" course and referring to curriculum document of foreign enginery specialty. Compared with "manufacturing technology foundation" course, "process of industry production" course more emphasizes implement and operation aspects in machine manufacture. The goal of the course is to let the students roundly know industrial production process of mechanical product, to make the students master the basic theory and knowledge of the mechanical manufacturing industry production process, know the purpose and implement means of machining, and to train students' skill of analyzing and solving problems. The "process of industry production" is a prerequisite course of teaching link such as "advanced manufacture" secondary level project, the first level project "design and manufacture of machine and electron system 3", production practice and graduation project. The main characteristic of CDIO engineering education reform is to put forward specific demands to related skills, and make various CDIO related skills of students be substantially improved. There are lots of concepts coming from engineering practice in the "process of industry production" course, due to lack of engineering practice experience, the students feel it is difficult to understand these concepts, which had to be crammed. The courses' content has highly comprehensive and practical, which puts forward higher demand for students' reviewing after class and ability to study independently [4].

EIP-CDIO cultivating program, which Shantou University had implemented since 2006, put explicitly forward devisable and comprehensive experiments must be arranged in teaching, which let students do it themselves as far as possible. The experiments should offer more opportunities of practice that can focus on cultivating students' skills of operation and experiment; can lead students to study actively, and emphasize cultivation and establishment of students' skills in discovering, analyzing and solving problems. And make experiments and other practice links can combine with classroom teaching better ${ }^{[1]}$. In accordance with the function of experiment teaching, it can be known that the experiment in "process of industry production" can cultivate student's CDIO related skills in Table 1. 
The content of experiment in course "process of industry production" is as follows: (1) "measurement of turning tool geometrical angle"; (2) "observation of cutting layer distortion and measurement of deforming coefficient"; (3) "effect of cutting force on machining accuracy"; (4) "effect of process parameter on the finished surface roughness".

Table 1The specific demands for various CDIO related skills training in "process of industry production" course

\begin{tabular}{|c|c|c|c|c|}
\hline & & Knowledge & Comprehension & Application \\
\hline \multirow{3}{*}{$\begin{array}{l}\text { 1Technical knowledge } \\
\text { and reasoning }\end{array}$} & $\begin{array}{l}\text { 1.1Knowledge } \\
\text { underlying science }\end{array}$ & & & $\sqrt{ }$ \\
\hline & $\begin{array}{l}\text { 1.2Core engineering } \\
\text { fundamental knowledge }\end{array}$ & & & $\sqrt{ }$ \\
\hline & $\begin{array}{l}\text { 1.3Advanced engineering } \\
\text { fundamental knowledge }\end{array}$ & & & $\sqrt{ }$ \\
\hline \multirow{5}{*}{$\begin{array}{l}2 \quad \text { Personal and } \\
\text { professional skills and } \\
\text { attitudes }\end{array}$} & $\begin{array}{l}2.1 \text { Engineering reasoning } \\
\text { and problem solving }\end{array}$ & & & $\sqrt{ }$ \\
\hline & $\begin{array}{l}2.2 \text { Experimentation and } \\
\text { knowledge discovery }\end{array}$ & & & $\sqrt{ }$ \\
\hline & 2.3 System thinking & & $\sqrt{ }$ & \\
\hline & $\begin{array}{l}2.4 \text { Personal skills and } \\
\text { attitudes }\end{array}$ & & & $\sqrt{ }$ \\
\hline & $\begin{array}{l}2.5 \text { Professional skills and } \\
\text { attitudes }\end{array}$ & & $\sqrt{ }$ & \\
\hline \multirow{3}{*}{$\begin{array}{lr}3 \text { Interpersonal skills: } \\
\text { teamwork } & \text { and } \\
\text { communication } & \end{array}$} & $\begin{array}{l}3.1 \quad \text { Multi-disciplinary } \\
\text { teamwork }\end{array}$ & & & $\sqrt{ }$ \\
\hline & 3.2 Communications & & & $\sqrt{ }$ \\
\hline & $\begin{array}{l}3.3 \text { Communications in } \\
\text { foreign languages }\end{array}$ & & & $\sqrt{ }$ \\
\hline \multirow{6}{*}{$\begin{array}{l}4 \text { Conceiving, } \\
\text { designing, } \\
\text { implementing, and } \\
\text { operating systems in the } \\
\text { enterprise and social } \\
\text { context }\end{array}$} & $\begin{array}{l}\text { 4.1 External and social } \\
\text { context }\end{array}$ & & $\sqrt{ }$ & \\
\hline & $\begin{array}{l}4.2 \quad \text { Enterprise } \\
\text { business context }\end{array}$ & & $\sqrt{ }$ & \\
\hline & $\begin{array}{lcc}4.3 \quad \text { Conceiving and } \\
\text { engineering systems }\end{array}$ & & & $\sqrt{ }$ \\
\hline & 4.4 Designing & & & $\sqrt{ }$ \\
\hline & 4.5 Implementing & & & $\sqrt{ }$ \\
\hline & 4.6 Operating & & & $\sqrt{ }$ \\
\hline
\end{tabular}

\section{Designing of Experiment in Courses "Process of Industry Production”}

The designed experiments should be guided by EIP-CDIO engineering education idea, and can take full advantage of the CDIO Innovation and Practice Center in the department of mechatronics engineering and its management features. It aims at coming true the cultivating goal in "Excellent Engineer Education and Training Plan" of the department of mechatronics engineering. After several years' experimental teaching, it can be known that following two aspects should be noticed in experiment design:

Improving the utilization ratio of machine tools and training more operation skills of students. In "effect of process parameter on the finished surface roughness" experiment, only the engine lathe is used at preliminary stage, and there were some problems in the experiment. In order to avoid these problems, CNC lathes are utilized in the experiment now. The merits of using CNC lathes are as follows: (1) Consolidating students' operation skills in CNC lathes: Although the sophomore 
students experienced the training of $\mathrm{CNC}$ lathe operation in the "metalworking practice" course, they will become strange to the machine when they are juniors. If CNC lathes are used in the experiment, students will have one more chance to operate, then their operational skills in CNC lathes can be consolidated; (2) Guaranteeing the accuracy of experiment data: In the cutting speed being higher, the experiment data may be not accuracy by using engine lathes, as the engine lathes is not so stability as CNC lathes; (3) Protecting the environmental hygiene of the center: when doing the "effect of cutting fluid on the finished surface roughness" experiment, CNC lathes can keep the court dry and prevent fluid from splashing students; (4) Guaranteeing students' safety: As the cutting speed is higher in the "effect of cutting speed on the finished surface roughness" experiment, students easy to be panic in operating engine lathes and the speed of scrap iron is very high too, which easy to endanger students' safety. However, these dangers can be avoided easily in using the CNC lathes.

Arousing students' initiative and positivity of taking part in experiments. There are 8 students in every experiment. And the students are divided into two to four groups according to the instruments and machines. The groups have to finish the experiment task under given time and get reasonable experiment result, which cultivates students' skill of cooperation. During the experiment students can select experiment parameters on their own, which improves students' initiative in the experiment. However, they should select the experiment parameters based on the reference book of course "process of industry production" rather than randomly. It must be noticed that different experimental conditions such as experiment instrument, machine tool, and experiment parameters between practical experiment and experiment case in the reference book.

When experiment equipments and instruments are ascertained, the selection of experiment parameters can directly influence experiment accuracy. Instructor will provide students a group of parameters before experiment. The group of parameters has been tried many times and its result is reasonable.

For instance, how to select the cutting thickness in the "affection of cutting thickness on chip deformation coefficient" experiment in order to get reasonable result? The cutting thickness selected is $0.04 \mathrm{~cm}, 0.08 \mathrm{~cm}, 0.1 \mathrm{~cm}$ respectively in the experiment. The reasons are as follows: Firstly, the spacing of cutting thickness is $0.04 \mathrm{~cm}, 0.02 \mathrm{~cm}$ respectively, which can remove the affection of feeding threaded rod clearance. However, it is not suitable to select too big thickness. The cutting edge will be badly worn and even broken down, which may affect the accuracy of experimental data; Secondly, the chip shape is more regular and easily to be measured that can decrease the measurement error; Lastly, it is not easy to generate built-up edge on cutting edge, the affection of built-up edge on experiment can be excluded.

In another example, how to select the cutting speed in the "effect of cutting speed on the finished surface roughness" experiment to get reasonable result? The speed chosen is 100rpm, 270rpm, 450rpm, 710rpm, and 900rpm respectively in the experiment. The built-up edge will be easily generated on cutting edge at the speed of $270 \mathrm{rpm}$, while it may be not generated at other speeds. Hence, the Ra (Roughness average) is the most high at the speed of 270rpm. The Ra at the speed of 710rpm is nearby with the Ra at the speed of 910rpm, which means that the Ra decreases smaller and smaller as the speed increasing. It is well-known that the Ra of finished surface will be affected by the built-up edge. So the experimental sequence is very important. In accordance with foregoing analysis the experimental order is as follows: 900rpm, 710rpm, 450rpm, 100rpm, and 270rpm. The experimental result is that the finished surface Ra increases and then decreases with the increasing of cutting speed, which is a reasonable result.

Some students' experimental results are not reasonable after experiment, but they have no time to find out the reasons in the experimental class time. Then in writing reports, they analyze the experiment data by the use of results in the reference book rather than experiment results. Consequently, they cannot understand directly the theoretical knowledge in the reference book. Now the center opens for students all day, they can apply to do it once again after the experimental class. Hence they can observe the experiment process more carefully, and then find out the mistakes in doing the experiment, which cultivates students' skill of discovering problems and solving problems 
and evokes students' thirst for knowledge. In a word, the open management of the center can arouse students' initiative and positivity of taking part in experiments.

\section{Achieved Awards}

The CDIO Innovation and Practice Center provides superior service for students' project implementention and experiment teaching, which enhances students' comprehensive quality and makes them get outstanding achievements in competitions at home and abroad [5]. For example, in the "Fifth National Match of Student Mechanical Creative Design in 2012", the Shantou University received 8 awards and five of them are the first prizes. The "self-balancing two-wheeled leisure vehicle" project got the first prize both in Guangdong province and nation, and the "household juicer" project won the first prize in the national preliminaries and final. Shantou University won 13 awards in "National Undergraduate Engineering Training Integration Ability Competition in 2013", "Sixth Central South, Hong Kong and Macao Regional Undergraduate Machine Creative Design and Manufacture Competition Final" and "National Challenge Cup".

Shantou University won the second prize by the "water-surface cleaning facility based on pump driving and image processing" project in the "CDIO Academy Students Project Competition in 2013" hold by MIT and Harvard University. There are 31 teams came from France, United State Canada, Russia, Singapore, Sweden, Vietnam and China and so on countries in the competition, and Shantou University is the unique students' team came from China.

Students are also approbated by society in vocational operation skills. For instance, most students got the turner professional certificate awarded by Department of Human Resource and Social Security of Guangdong Province.

\section{Conclusions}

The CDIO Innovation and Practice Center has formed its special operational mechanism after several years' exploration. These mechanisms either ensure the center operate normally or meet students' demands for teaching and competition projects and their training for vocational operation skills, and make experiment teaching more neatly.

\section{Acknowledgments}

The authors wish to thank for the financial support of the School-level Educational Reform Project of Shantou University in 2013.

\section{References}

[1] Gu Peihua, Shen Minfen, Li Shengping, Zhuang Zhemin, Lu Xiaohua and Xiong Guangjing: Research in Higher Education of Engineering, (2008) NO.1, pp.12-20.(in Chinese)

[2] Song Jinfen, Yu zhao: China Education Innovation Herald, (2012) NO.16 ,pp196. (in Chinese)

[3] Zheng Jiamao:Research and exploration in laboratory, vol. 26 (2007), NO.10, pp. 2.

[4] Zhang Ziqiang: Advances in Educatiion Research, vol. 22 (2013), pp.305.

[5] Information on http://mecdio-lab.stu.edu.cn/Index.php/cdio/student. 